\title{
Industrial policy, comparative advantages and growth
}

\section{Jaime Ros \\ Research Fellow, \\ Helen Kellogg Institute \\ for International Studies, \\ Notre Dame University, \\ Indiana, USA \\ jaime.ros.1@nd.edu}

This article analyses the relations between the international specialization pattern and growth. For this purpose, it adopts as its analytical framework the recent literature emphasizing the importance of initial conditions and public policies, and not only factor endowment. It also analyses the empirical and economic policy implications of this approach. After an introduction (section I), section II presents the analytical framework: a model with two internationally tradeable goods sectors and a non-tradeable inputs sector, with increasing returns to scale and dynamic pecuniary externalities. Section III draws the implications of the analysis in terms of the effects that industrial policies can have on the specialization pattern and the growth rate, while section IV does the same with respect to the initial conditions and real and monetary shocks. Section V examines the empirical information on the relations between the specialization pattern, the capital accumulation rate and growth, and finally section VI sums up the main conclusions of the study with regard to the scope and limitations of industrial policy. 
I

\section{Introduction}

In the literature (both old and new) on international trade, there are a number of contributions which analyse the way in which the international trade specialization pattern can affect growth: the "infant industry" argument, Prebisch's and Singer's theories on the terms of trade of primary commodities, or the multisectoral models with different rates of learning in the new international trade theory. A common feature of these contributions is that the specialization pattern of an economy, as determined by its comparative advantages, may not be the same as the specialization pattern giving the greatest economic benefits in the long term. This may be because the static comparative advantages of the economy do not coincide with its dynamic comparative advantages, because of technological externalities associated with learning processes, or because the evolution of the terms of trade is such that the economy would do better to abandon the specialization pattern associated with static comparative advantages. In this case, an industrial policy which reallocates resources to the sectors with dynamic advantages, through subsidies or customs tariffs, is justified if there are flaws in the factor markets (especially the lack of a perfect capital market).

There is another way of approaching the subject of the way in which the specialization pattern can affect the long-term growth rate, that is, when a given factor endowment does not mean that there is only one possible specialization pattern and the different specialization patterns consistent with the same factor endowment have different dynamic effects. This may be due to the existence of dynamic pecuniary externalities associated with different linkages with sectors of goods which are not tradeable, or only imperfectly tradeable, on the international market. In this case, there is not a conflict between static and dynamic comparative advantages which could, in theory, be satisfactorily solved if the capital market were perfect. There is rather a difference between a very high capital yield on a set of coordinated investments and the yield that could be obtained by an individual investor and which is very low or insufficient to shift capital to the sectors with high growth potential. When the economy specializes in a less dynamic pattern, the problem is thus due to a lack of coordination. Recent models based on this approach may be found in Rodrik (1995), Rodríguez-Clare (1996), Ciccone and Matsuyama (1996), Skott and Ros (1997) and Ros (2000, chapter 9). It hardly seems necessary to note that the subject is closely linked with the debates on the role played by industrial policy in the examples of rapid growth after the war and the recent empirical literature on the effects of the international trade specialization pattern on the growth rate (Matsuyama, 1992; Sachs and Warner, 1997; Sala-i-Martin, 1997).

\section{II}

\section{The analytical framework}

In neoclassical theory, the pattern of specialization is unequivocally determined by the factor endowment of the economy (along with technology and the terms of trade) because, regardless of the initial conditions, the economy is assumed to converge towards a pattern of specialization which can be explained by the factor endowment. At the other extreme of the theoretical scale, some models in the new international trade theory consider productivity growth to be the result of learning processes and leave out factor endowment as a determinant of comparative advantages (see, for example, Krugman, 1987). In this case, the specialization pattern cannot be determined independently of the initial conditions and past history. Accidents - that is to say, disturbances in the real sphere, such as a temporary boom in natural resources, or monetary disturbances such as temporary exchange rate overvaluation- are of decisive importance in 
determining the pattern of specialization. Industrial policy also becomes of crucial importance in the acquisition of new comparative advantages. The model presented in this section may be seen as an extension of a neoclassical model which admits the existence of increasing returns to scale in the production of nontradeable inputs, or as a model based on the new international trade theory -like that of Krugman (1987) on the "competitive consequences of Mrs. Thatcher"which discards the assumption of Ricardian-type technology and introduces non-tradeable goods. As we shall see, in these conditions the factor endowment, the initial conditions and the policies adopted all play a role in determining the specialization pattern.

\section{The basic model}

Let us consider an economy with three sectors. Sector 1 produces a tradeable good using capital and labour, on competitive conditions and with constant returns to scale. Sector 2 also produces a tradeable good, using capital and non-tradeable inputs (we are leaving out the labour factor for the purpose of simplicity and in order to emphasize that what this sector is producing, on competitive conditions and with constant returns to scale, is a good which makes intensive use of capital). In both sectors, the technology used is of the CobbDouglas type. Sector 3 produces the non-tradeable inputs used in sector 2 . These inputs are produced using labour and with increasing returns to scale. These intermediate goods can represent a set of manufactured inputs and production services (such as banking and insurance services), as in the model used in RodríguezClare (1996), or they can be a set of infrastructural goods and services (energy, transport and communications), as in Skott and Ros (1997). Formally, input $I$ of the set of intermediate goods $I i$ may be represented as:

$$
I=\left(\Sigma(1 / n) I i^{\sigma}\right)^{1 / \sigma} \quad 0<\sigma<1,
$$

where $n$ is the number of intermediate goods, assumed to be a given value.

Alternatively, sector 3 may be considered as an industry assembling a set of components $I i$ produced under conditions of increasing returns: ${ }^{1}$

$$
I=n^{a}\left(\Sigma(1 / n) I i^{\sigma}\right)^{1 / \sigma} \quad a>1 \quad 0<\sigma<1,
$$

where $I$ is the output of sector 3 and $n$ is the number (not fixed) of components produced. In this case, we

\footnotetext{
${ }^{1}$ This is what is known as Dixit-Stiglitz and Ethier's specification (see Ethier, 1982).
}

interpret each of these components as a link in the production process. An increase in the number of components means a finer division of labour. Because of the existence of economies of specialization, this greater division of labour makes it more productive, by increasing differentiation and generating new processes and auxiliary industries (see Kaldor, 1967, p. 14). There are two differences between this specification of sector 3 and the previous one. Firstly, the economies (of specialization) taken into account here are external to the enterprise, unlike the economies of scale, internal to the plant, described in the first specification. This is what the second specification implies: as the parameter $a$ is greater than one, an increase of $x \%$ in the number of components, keeping ( $n$ Ii) constant, generates more units of $I$ than an increase of $x \%$ in each component, keeping $n$ constant. Secondly, in the present specification the number of intermediate goods, instead of being given, is endogenous and is determined by the size of the market for sector 3 .

In the following sections, the presentation will be based on the first specification, characterized by the presence of internal economies of scale, although qualitatively similar results can be obtained using the second specification. At all events, the key difference between sectors 1 and 2 is that whereas sector 2 has a backward linkage with the sector producing inputs, there are no linkages in the case of sector 1 . The integrated sector 2 and 3 may be seen as a "production complex" characterized, as we shall see, by effects which are external to each one of the two sectors that make it up.

\section{a) Multiple equilibria and pecuniary externalities}

In an economy like that considered here, under certain conditions there can be multiple market equilibria. A formal analysis of the existence of multiple equilibria is given in the appendix. Here, we will limit ourselves to describing the basic assumption. In order to understand why there are multiple equilibria, we may begin by noting that an equilibrium in which sectors 1 and 2 exist side by side is an unstable equilibrium. Thus, let us imagine an economy in which the two tradeable goods sectors exist side by side and both have the same levels of profitability. In this situation, the reallocation of a small amount of capital to sector 2 has the effect of increasing its relative profitability, for the expansion of the market for sector 3 (associated with the reallocation of capital to sector 2) tends to reduce the cost of producing the intermediate goods in question, 
with a favourable effect on the rate of profitability of sector 2. This increase in the relative profitability of sector 2 causes capital to flow to it and hence further increases its rate of profitability. In contrast, reallocation of capital to sector 1 has the opposite effect of reducing the relative profitability of sector 2 , by reducing the size of the market for sector 3 and raising the cost of producing intermediate goods. The capital therefore tends to flow to sector 1 , further increasing its relative profitability. In both cases the process continues up to the point of the complete disappearance of one of the two tradeable goods sectors and total specialization of the economy in the other sector.

The second thing to be noted is that an equilibrium with specialization in sector 1 always exists in the economy in question, regardless of whether there are multiple equilibria or not. When the levels of capital invested in sector 2 are low, the profitability of the sector tends towards zero, because of the high cost of producing the necessary intermediate goods, but it continues to be positive in sector 1, whatever the level of the stock of capital. There are therefore some allocations of capital, if the levels of capital invested in sector 2 are sufficiently low, in which sector 1 is more profitable than sector 2 . As we shall see below, the fact that there is always an equilibrium with specialization in sector 1 is due to the assumption that that sector does not use inputs produced by sector 3 .

As there is always an equilibrium with specialization in sector 1 , it follows that the existence of an equilibrium with specialization in sector 2 ensures the existence of multiple equilibria. There is an equilibrium with specialization in sector 2 if the profitability of that sector, when all the capital is invested in it, is greater than that of sector 1 (taking account of the market equilibrium wage when the entire labour force is employed in sector 3). As demonstrated in the appendix, the existence of such an equilibrium depends on the capital and labour endowments of the economy and the terms of trade between sectors 1 and 2. In particular, in order for there to be an equilibrium with specialization in sector 2 , the total stock of capital must be large enough to ensure that, when it is entirely invested in sector 2 , the prices of the intermediate goods must be low enough and the wages high enough to make sector 2, which makes intensive use of capital and inputs, more profitable than sector 1 , which makes intensive use of labour. The higher the relative price of the goods produced by sector 1 (with respect to those of sector 2), the greater the size of the stock of capital needed for there to be multiple equilibria, since that higher price increases the relative profitability of sector 1. The size of the stock of capital needed also increases with the number of enterprises $n$ in the intermediate goods sector, which adversely affects the productivity of sector 3 and the profitability of sector $2 .^{2}$

The existence of multiple equilibria is associated with the presence of pecuniary externalities (although the presence of such externalities is not of itself a sufficient condition, since there may be a single equilibrium with specialization in sector 1). Thus, the existence of increasing returns to scale in the intermediate goods sector means that production decisions in sector 3 and investment decisions in sector 2 have significant external effects. An increase in the production of one of the intermediate goods adversely affects demand for other inputs, but it lowers the price of the overall set of intermediate goods and increases both the total input of intermediate goods and the rate of profitability of sector 2 . In addition to these static effects, there is also a dynamic externality: higher profitability of sector 2 encourages capital accumulation in that sector and leads to an increase in future demand for intermediate goods. On the investment side, the atomized producers in sector 2 take all prices as given and do not take into account the external effects that the greater stock of capital has on future demand for intermediate goods or the tendency for the prices of those goods to go down as the production costs of sector 3 are reduced.

As a result of these dynamic pecuniary externalities, an economy specializing in sector 1 will be trapped in that specialization pattern if all the enterprises follow a line of behaviour which is rational for each of them. As all the capital is invested in sector 1 , the demand for intermediate goods is non-existent and the production costs of those goods are extremely high. Consequently, the profitability of sector 2 is so low that the capital is invested in sector 1 . This keeps the production costs of sector 3 high and lowers the profitability of sector 2 .

\section{b) The two patterns of specialization compared}

Why does it matter if the economy is trapped in a trade pattern specializing in sector 1 ? The reason is that the two specialization patterns are not equivalent in terms of economic well-being (nor, as we shall see below, in

\footnotetext{
2 This conclusion does not apply to the model with the second specification of sector 3 , in which the number of enterprises is endogenous and positively affects the productivity of the sector.
} 
terms of growth potential). As demonstrated in the appendix, the existence of multiple equilibria ensures that the rate of profitability is higher in the equilibrium specializing in sector 2 , provided that that sector makes more intensive use of capital than sector 1. It may be assumed that the high level of the stock of capital needed for there to be multiple equilibria will generate relatively high wages, and this will tend to depress the rate of profitability of sector 1 , which makes intensive use of labour. On the other hand, at sufficiently high levels of capital stock, real wages are also higher in the equilibrium specializing in sector 2 , for at sufficiently high levels of capital stock the greater scale of sector 3 will have made this sector more productive and reduced the relative price of the intermediate goods produced. As a result, as the stock of capital increases the capital/ intermediate inputs ratio in the output of sector 2 tends to go down, and the expansion of sector 2 at the expense of sector 1 generates an excess of demand for labour, with a positive impact on real wages.

\section{Extensions}

\section{a) The model involving the use of inputs in sector 1}

In the previous model, the technology available in sector 1 does not use intermediate goods. Let us now assume, however, that sector 1 does use intermediate goods, although less intensively than sector $2 .{ }^{3}$ The demand for intermediate goods no longer comes exclusively from sector 2 and therefore does not depend on the amount of capital invested in it. The capital invested in sector 1 now also affects the demand for intermediate goods and, ultimately, the relative price of those goods with respect to those produced by sector 2 . Consequently, the profitability of sector 2 will now depend not only on the capital invested and the wages in that sector, but also on the capital invested in sector 1 and, hence, the total stock of capital. This means that there will be a sufficiently high value of the stock of capital which, when the whole of that stock is invested in sector 1 , will make the relative price of the intermediate goods sufficiently low and wages sufficiently high to cause the rate of profitability of sector 2 to be higher than that of sector 1 , both rates being calculated at the market equilibrium values for

\footnotetext{
${ }^{3}$ This is the case analysed by Rodríguez-Clare (1996), in a model similar to that presented in the appendix. As well as providing for the use of intermediate inputs in sector 1, Rodríguez-Clare's model adopts Dixit-Stiglitz and Ethier's specification for sector 3 instead of the specification with a fixed number of intermediate inputs.
}

wages and intermediate goods. When the total stock of capital reaches that value, the equilibrium with specialization in sector 1 disappears, since sector 2 is more profitable than sector 1 even when the whole of the capital is invested in the latter. Unlike the previous model, it is no longer true that there is always an equilibrium with specialization in sector 1 , whatever the size of the total stock of capital.

We now have three configurations. First, for a range of low values of the capital stock there is a single equilibrium. In this equilibrium, the economy specializes in the production of tradeable goods in sector 1 , and a small sector 3 exists side by side with sector 1 . The trade specialization must be in sector 1 , not sector 2, because sector 1 is the sector which uses intermediate goods least intensively and is therefore the only one capable of surviving with the high production costs prevailing in the intermediate goods sector.

In a range of intermediate values of the capital stock, there are two stable equilibria, with specialization in sector 1 and sector 2 respectively. The total stock of capital is sufficiently large to generate a productive intermediate goods sector and make sector 2 viable, but only if the capital is invested in sector 2. If the capital is invested in sector 1, the intermediate goods market will not be sufficient to make investing in sector 2 profitable. In the equilibrium with specialization in sector 2, however, the rate of profitability is greater and the real wage is at least as high as in the equilibrium with specialization in sector 1 . The equilibrium with specialization in sector 2 is therefore superior in terms of Pareto's criterion to the equilibrium with specialization in sector 1 , not just for a certain minimum value of the capital stock but for the whole range of values of the capital stock where there are multiple equilibria.

Finally, for large values of the capital stock we have a single equilibrium once more. The capital stock is sufficiently large not only to make sector 2 viable but also to cause the equilibrium with specialization in sector 1 to disappear. The low prices of intermediate goods and high wages make it profitable for individual investors to shift from sector 1 to sector 2, even when all the capital is initially invested in sector 1 . When this is done, the prices of intermediate goods and wages move in such a way as to strengthen the relative profitability of sector 2 , and eventually the whole of the capital shifts to that sector. Sector 1 becomes nonviable because of the high wages associated with the relatively high capital/labour ratio of the economy. 
b) The model with skilled labour in the intermediate goods sector

Let us now assume that the technology employed in sector 3 uses skilled labour (whereas sector 1 uses unskilled labour). ${ }^{4}$ Together with the size of the capital stock, the level of skills of the labour force thus becomes a further factor influencing the existence of multiple equilibria, for a higher level of skills may make up for the high costs resulting from a small market for intermediate goods produced under conditions of increasing returns and thus tends to reduce the size of the capital stock required for there to be an equilibrium with specialization in sector 2 . Similar conclusions may be reached if it is sector 2, rather than sector 3, which makes intensive use of skilled labour: whereas the high price of intermediate goods tends to depress the relative profitability of sector 2 , an abundance of skilled labour tends to increase it, so that sector 2 can be viable depending on the allocation of the capital stock. At all events, the existence of multiple equilibria can be the result of different mixes of levels of skills and capital stocks, rather than simply a range of intermediate values of the capital stock.

\section{III}

\section{Industrial policy and growth}

Many developing countries have adopted industrial policies in an attempt to speed up the rate of industrialization and the economic growth rate. The results have been mixed, judging from the variety of different results obtained using similar policies. This explains why the efficacy of these policies is a matter of controversy and why there are different opinions as to whether these policies have made a difference and, if so, whether their effects have been positive or negative. This is so even though both observers and policy-makers have amply documented the role of industrial policy in achieving the rapid industrialization of East Asia (see Amsden, 1989; Wade, 1990). This situation goes a long way towards explaining why there is no consensus on the key question of how, and in what conditions, industrial policy can significantly alter the rates of capital accumulation and growth. The analytical framework set forth earlier in this article sheds some light on this question, as we shall see below.

Let us begin by noting that in neoclassical international trade theory factor endowment, technology and the terms of trade are considered to unequivocally determine the pattern of comparative advantages and specialization of an economy. In the analytical framework presented in the previous section,

\footnotetext{
${ }^{4}$ A similar case is analysed by Rodrik (1995). In the present analysis, the existence of multiple equilibria is associated with a relatively high level of skills of the labour force, together with a relatively small stock of capital.
}

in contrast, the existence of multiple market equilibria associated with different patterns of specialization but with the same factor endowment, technology and terms of trade makes the very notion of comparative advantage ambiguous. More exactly, when a single equilibrium exists, regardless of whether it is with specialization in sector 1 or 2 , it makes sense to say that the economy displays a comparative advantage in the corresponding sector, and the market incentives will induce the economy to specialize in the sector which has a comparative advantage. When there are multiple equilibria, however, there is longer a clear answer to the question of where the comparative advantage in trade lies. It could be said (using a phrase which would make no sense in the context of neoclassical theory) that the economy is in a state of transition between a pattern of comparative advantages which has disappeared and another which has not yet emerged.

The different specialization patterns associated with the same factor endowment have different growth implications. Let us consider, for example, the model with intermediate inputs in the two tradeable goods sectors and assume that the conditions for the existence of multiple equilibria are fulfilled. We will compare two economies which are identical in all aspects (factor endowment, rate of saving, size of the labour force) except their pattern of specialization, since one is specialized in sector 1 and the other in sector 2 . As we have seen earlier, real wages and the rate of profitability are higher in the second economy. Consequently, this economy will also have a higher per capita income, so 
that for the same rate of saving and investment it will have higher rates of capital accumulation and growth. The superiority of the growth rate of the economy specializing in sector 2 will be even greater if there is international capital mobility, since this capital will tend to flow to the economy offering the highest return on capital and that economy's rate of investment will therefore tend to be higher.

This means that if an economy is specialized in sector 1 , an industrial policy which reallocates resources to sectors 2 and 3, leading to a specialization pattern based on those sectors, will raise the growth rate of the economy. Moreover, in the absence of an industrial policy an economy specializing in sector 1 will not move spontaneously towards the high-growth equilibrium. With the prices and wages prevailing in the equilibrium with specialization in sector 1 , the rate of profitability of sector 2 will be below that of sector 1 , and no individual investor will find it profitable to invest in sector 2. Individual incentives, as measured by the market, will keep the economy on the low growth path associated with specialization in sector 1, as long as that equilibrium persists. Only when a sufficiently large mass of investors shift simultaneously to sectors 2 and 3 will the profitability of sector 2 be more attractive than that offered by sector 1 . However, this requires policy interventions in order to provide the necessary coordination among producers.

It is quite true that eventually the economy specializing in sector 1 will obtain a comparative advantage in sector 2 through the capital accumulation process itself. When that happens, the profitability of sector 2 will be greater than that of sector 1 and the market incentives will lead the economy to specialize in sector 2 , since the equilibrium with specialization in sector 1 will have disappeared. During the transition to the stock of capital needed for this to happen, however, an economy which specialized in sector 2 from the start will have a higher growth rate. The high and sustained growth rate of the East Asian economies may be understood as the result of a succession of policy interventions which speeded up the transitions between different patterns of production and international trade specialization. It is hard to imagine how a development model driven primarily by the market forces, such as the developing countries are currently being recommended to adopt, can pass through these transitions so successfully. This is not because there are no examples of successes based on the market (this is open to debate), but because theory suggests exactly the opposite: that the market incentives can hardly solve efficaciously (or at least efficiently) the problems of coordination that arise in the transition.

Successful policy interventions aimed at speeding up the transition form the basis for Rodrik's interpretation of how Korea and Taiwan became rich (Rodrik, 1995; see also Amsden, 1989, and Wade, 1990). The argument is that, rather than their export orientation, the distinctive feature of these examples of growth was the sharp and sustained increase in their investment rates in the early 1960s. Through a variety of policy interventions, subsidizing and coordinating investment projects, government policy succeeded in reallocating resources to modern industries making intensive use of capital and skilled labour. With growing returns in these activities, such reallocation raised the profitability of capital and propelled the economy towards a high growth path. Outward orientation was a consequence of this, because the higher rates of investment increased the demand for imported capital goods. The relatively high level of skills of the labour force in both countries was a necessary condition for the success of the industrial policy adopted.

At the same time, the analysis made shows the limitations of industrial policy when the conditions needed for its success (the existence of multiple equilibria) are absent. Let us assume that there is a single equilibrium in the economy, with specialization in sector 1 . In this case, industrial policy cannot improve the results of the market forces. Let us consider, for example, a policy which seeks to reallocate resources to sectors 2 and 3. Let us assume that this policy is successful in reallocating new investments to sector 2 . Precisely because there is no equilibrium with specialization in sector 2 , wages in this economy will fall compared with their value for equilibrium with specialization in sector 1 . Profitability will also tend to fall, because the stock of capital is small and the costs of the intermediate goods produced are therefore high. With a rate of profitability in sector 2 which is less than that of sector 1 (at market prices and wages), the changes in relative prices which must be induced in order to make sector 2 viable would mean an even greater fall in real wages. On the other hand, when there is a single equilibrium with specialization in sector 2 an industrial policy is not needed. The economy has a clear comparative advantage in sector 2 , and the market incentives will of themselves lead the economy to adopt the specialization pattern with the highest growth path.

This means that the existence of externalities is not sufficient to justify an industrial policy. When 
industrial policy cannot do anything to improve the market results (when there is only an equilibrium with specialization in sector 1) or is actually unnecessary (when there is only an equilibrium with specialization in sector 2) this is due ultimately to the fact that, as we saw earlier in this article, the presence of static and dynamic externalities is not sufficient to ensure the existence of multiple equilibria.

This analysis has other interesting connotations. In the literature on the effects of industrial policy, the variety of results obtained has tended to be associated with the variety of policies adopted (see for example Amsden, 1989). Thus, for example, the success of the industrial policies applied in East Asia compared with the less successful results obtained in Latin America has been associated with the fact that in the first case the incentives for firms or sectors were granted in exchange for the attainment of clearly defined goals, and the time horizon for the operation of the policies was clearly delimited. These differences undoubtedly must have contributed to the success of the Asian model, but our analysis also suggests that the success of an industrial policy depends very much on the existence of the necessary conditions for its application. A single given industrial policy may be effective or not, depending on this. In this context, it is easy to understand the importance that the initial level of skills of the labour force in the East Asian countries had for their emergence as industrialized countries in the early 1960s. This relatively high level of skills had existed for a long time before, but it only became crucial later on, when it gave viability to an industrial policy which reallocated resources to modern sectors making intensive use of physical and human capital. Our analysis also makes it possible to understand the role played by the particular design of industrial policies in East Asia. By limiting the time horizon and the incentives offered, these policies incorporated selfcorrection mechanisms. If the conditions needed for the industrial policy to be effective were lacking, its lack of viability was clearly evident as soon as it began to be applied. This made it possible to turn back and thus minimize the loss of resources that persistence with a non-viable policy would have involved.

\section{IV}

\section{The terms of trade and the "Dutch Disease"}

The size of the capital stock and the level of skills of the labour force are not the only factors affecting the existence of multiple specialization patterns. As already mentioned, the existence of multiple equilibria also depends on the terms of trade between the goods produced by sectors 1 and 2 . In order to illustrate the role of these terms, let us consider an economy specializing in the labour-intensive sector (sector 1), and let us assume that with the passage of time the entry onto the international market of new producers with low wage costs tends to reduce the relative prices of labour-intensive goods. This has the effect of generating an equilibrium with specialization in sector 2 , without this necessarily causing the economy to shift to that higher-growth equilibrium. In a way, the economy is losing its competitiveness in sector 1, without however acquiring a comparative advantage in sector 2 . This situation corresponds to that of a number of semiindustrialized countries which on the one hand are facing strong competition from new low-wage producers of labour-intensive goods, while on the other they are not as yet capable of competing with the more efficient producers of capital-intensive goods in the industrialized countries. If we interpret sector 1 as a sector producing primary commodities, this transition describes the balance of payments problems and the eventual beginning of industrialization of countries with abundant natural resources which are facing a deterioration in the terms of trade of their exports of primary commodities.

Whichever of these interpretations is adopted, the transitional economy whose terms of trade have become unfavourable will continue to specialize in the goods produced by sector 1 (primary commodities or labourintensive goods) until it may reach the high levels of capital which make sector 2 profitable from the point of view of individual investors (unless right from the start the drop in the prices of the goods produced by sector 1 is so great that it eliminates the equilibrium with specialization in sector 1). This is so simply because the equilibrium with specialization in sector 1 is a locally stable equilibrium: no individual investor 
alone will find the investment opportunities in sector 2 more attractive than those in sector 1 . In the transitional period, the economy will suffer a reduction in its growth rate as a result of the decline in the relative price of sector 1's goods. As equations [7] and [14] in the appendix show, the rate of profitability in that economy is an inverse function of the relative price of the goods produced in sector 2 . Insofar as the rate of accumulation depends on this profitability, the reduction in the relative price of the goods produced by sector 1 will adversely affect capital accumulation and growth. In turn, the lower rate of accumulation will prolong the transition to the level of capital stock needed to make the production of goods in sector 2 spontaneously profitable. When there is such a "slow growth trap", economic policy intervention may make a substantial difference in the medium-term growth rate.

Another implication of the analysis confirms the fears expressed in the literature on the "Dutch Disease" (for a review of this literature, see Corden, 1984). Let us assume that sector 1 is natural resource-intensive and the economy is specialized in sector 2. With the initial terms of trade and capital stock there are multiple equilibria. Starting from this situation, the relative price of sector 1's goods subsequently rises to such a point that sector 1 is more profitable than sector 2 , so that the equilibrium with specialization in sector 2 disappears. This shifts resources from sectors 2 and 3 to sector 1 and the economy becomes specialized in sector 1. Later on, the relative price of sector 1's goods returns to its initial level, causing the reappearance of the equilibrium with specialization in sector 2 , but there is not a corresponding shift in resources to sectors 2 and 3 . The economy continues to be specialized in sector 1 because, as we assumed, with the initial terms of trade there are multiple equilibria and the profitability of sector 1 is therefore greater than that which an individual investor can obtain in sector 2 when the economy is specialized in sector 1 . The boom in natural resources, although only temporary, has had permanent effects on the specialization pattern of the economy and the long-term growth rate.

\section{$\mathrm{V}$}

\section{Empirical evidence ${ }^{5}$}

\section{Trade specialization and growth}

The main conclusion to be drawn from the foregoing analysis is that the specialization pattern is a determining factor in the economic growth rate. There are two channels by which this influence is exerted. Firstly (controlling for other factors), the capital yield, and hence the investment rate, tend to be higher in the specialization pattern based on industries with increasing returns. Secondly, for the same level of income per worker, specialization in industries with increasing returns is associated with a higher product/ capital ratio. This means that, even if the rates of investment are the same, the rates of capital accumulation and growth will be higher when the economy is specialized in industries with growing returns. Let us now look at the empirical validity of these relations.

\footnotetext{
${ }^{5}$ This section is based in part on Ros (2000), chapter 9, sections 3 and 4 .
}

It is worth noting, first of all, that the reallocation of resources to modern industries making intensive use of capital and skilled labour was accompanied in South Korea and Taiwan, as predicted in our analytical framework, with an increase in capital yields (and also in the rate of investment). In South Korea, profit rates in manufacturing rose from $16 \%$ in $1954-1956$ to $28 \%$ in 1957-1962 and 35\% in 1963-1970 (Hong, 1993, cited by Rodrik, 1995). In Taiwan, profitability increased after the late 1950s in the majority of manufacturing sectors except traditional industries such as textiles and wood products (Lin, 1973, cited by Rodrik, 1995).

Let us now look at the relation between specialization and growth through a cross-country analysis. The first question that arises is how to measure the pattern of specialization. As the level of income of a country rises, its trade pattern changes. Typically, the economy changes from being a net importer of manufactures to being a net exporter, and manufactures increasingly dominate its foreign trade. As the level of income affects the growth rate in ways which are independent of the pattern of specialization, it would 
be useful to have an indicator of trade specialization which isolates the effects of resource endowment from those of the policies applied and excludes the influence of the level of income on the trade pattern.

Such an indicator may be found in Chenery and Syrquin (1986). It consists of their index of trade orientation, which can be used to measure the bias towards manufactures in the composition of exports of goods, after adjustment for the income level and size of each country. ${ }^{6}$ The index measures, then, the degree to which an economy specializes in manufactures as a result of factors other than size and income (resource endowment and policies). This index is available for 1975, for 34 countries (including Hong Kong and Taiwan $)^{7}$, many of which were semi-industrialized in the 1970s.

We will also consider a smaller sample of 22 countries for which both the trade orientation index and the Leamer index of intra-industry trade and other features of foreign trade are available. These 22 countries were grouped according to their trade orientation index as follows:

i) countries with a positive bias towards exports of manufactures, mostly from East Asia and Southern Europe: Egypt, Greece, Hong Kong, Israel, Japan, Morocco, Portugal, Singapore, Spain and Yugoslavia;

ii) countries with a moderate bias towards exports of primary goods, mostly including Latin American and East Asian countries: Colombia, Costa Rica, Malaysia, Philippines, Thailand and Turkey; and

iii) countries with a strong bias towards exports of primary goods, mostly consisting of Latin American countries: Argentina, Brazil, Dominican Republic, Ecuador, Ivory Coast and Peru.

Table 1 summarizes the information available for this smaller sample of 22 countries: for the sample in

\footnotetext{
${ }^{6}$ This means measuring, for a given country, the deviation between the observed bias towards manufactures and the bias predicted for a typical country of similar income level and size. The trade orientation index of Chenery and Syrquin (1986) actually measures the bias towards primary exports. What we have done is to use this index by multiplying it by -1 , which gives us the bias towards manufactures.

${ }^{7}$ Algeria, Argentina, Brazil, Chile, Colombia, Costa Rica, Dominican Republic, Ecuador, Egypt, Greece, Guatemala, Hong Kong, Iran, Iraq, Israel, Ivory Coast, Japan, Malaysia, Mexico, Morocco, Peru, Philippines, Portugal, Singapore, South Korea, Spain, Syria, Taiwan, Thailand, Tunisia, Turkey, Uruguay, Venezuela and Yugoslavia.
}

question it reveals a positive relation between the bias towards exports of manufactures and the investment rate. Table 2 presents cross-country correlations for the sample.

Table 3 gives correlations for the larger sample ( 34 countries); the correlation coefficient between the bias towards manufactures and the investment rate is 0.35 . This is exactly what was implied by the models in section II, which suggest that specialization in industries with increasing returns (a bias towards manufactures) should have a positive effect on the investment rate.

As already noted, another implication of these models concerns the effect of the specialization pattern on the rate of capital accumulation, for a given investment rate. As table 2 shows, the correlation between the trade orientation index (which measures the degree to which an economy specializes in the export of manufactures) and growth is very high (0.73): higher than the correlation between the trade orientation index and the investment rate. Also noteworthy is the very significant coefficient of the trade orientation index in a regression of the growth rate with this index, the investment rate, and the initial level of GDP per worker:

$$
\begin{aligned}
\mathrm{g}= & 2.02+0.09 I / Y+1.47 \text { OC }-0.0002 Y / L_{60} R^{2}=0.75 \\
& \text { (3.73) (4.02) (4.39) (-4.42) }
\end{aligned}
$$

where $g$ is the growth rate of the GDP per worker (1960$1990) ; I / Y$ is the real investment rate (1970-1980); OC is the trade orientation index of Chenery and Syrquin, 1975 , and $Y / L_{60}$ is the real GDP per worker in 1960. The $t$ statistics are given in parentheses.

This equation indicates that, for the same initial income and investment rate, countries which specialized in the export of manufactures grew faster during the 1960-1990 period than primary commodity exporters. If we interpret sector 1 of the model in the first section as a sector which makes intensive use of natural resources and has few linkages with activities having increasing returns, the equation illustrates the basic implications of the model in terms of the effects of investment allocation on growth. The initial level of GDP per worker also has a very significant (negative) coefficient in the regression. This suggests that in this group of 34 semi-industrialized countries there is a tendency towards convergence: other conditions being equal, the countries with a lower level of income tended to grow faster. As the models examined previously indicate, however, this convergence was conditioned by the specialization pattern: the economies specializing in the export of manufactures converged towards high levels of income faster than those specializing in 
TABLE 1

22 countries: Trade orientation, investment and growth ${ }^{\mathrm{a}}$

(Averages per group of countries)

\begin{tabular}{|c|c|c|c|}
\hline & \multirow[t]{2}{*}{$\begin{array}{c}\text { Bias towards } \\
\text { export of manufactures }\end{array}$} & \multicolumn{2}{|c|}{$\begin{array}{c}\text { Bias towards } \\
\text { export of commodities }\end{array}$} \\
\hline & & Moderate & Strong \\
\hline Trade orientation index 1975 & 0.45 & -0.10 & -0.45 \\
\hline Rate of investment & 24.8 & 19.1 & 19.5 \\
\hline Growth rate & 4.1 & 2.8 & 1.5 \\
\hline Foreign trade share & 84.8 & 48.5 & 39.2 \\
\hline Trade intensity (Leamer 1) & 0.08 & 0.04 & -0.05 \\
\hline Index of intra-industry trade & 0.56 & 0.30 & 0.17 \\
\hline Number of countries & 10 & 6 & 6 \\
\hline
\end{tabular}

a For definitions and sources, see text of article and notes to table 3.

TABLE 2

22 countries: Cross-country correlations ${ }^{a}$

\begin{tabular}{lcccc}
\hline & $\begin{array}{c}\text { Trade orientation } \\
\text { index 1975 }\end{array}$ & $\begin{array}{c}\text { Intra- } \\
\text { industry trade }\end{array}$ & $\begin{array}{c}\text { Trade } \\
\text { intensity }\end{array}$ & $\begin{array}{c}\text { Foreign trade } \\
\text { share }\end{array}$ \\
\hline Trade orientation index 1975 & 1.00 & 0.69 & 0.42 & 0.35 \\
Intra-industry trade & & 1.00 & 0.73 & 0.71 \\
Trade intensity & & & 1.00 & 0.85 \\
Foreign trade share & & & 1.00 \\
\hline
\end{tabular}

${ }^{a}$ For definitions and sources, see text of article and notes to table 3.

TABLE 3

34 countries: Cross-country correlations

\begin{tabular}{lcccc}
\hline & $\mathrm{TO}_{1975}{ }^{\mathrm{a}}$ & $\mathrm{I} / \mathrm{Y}_{70-80}$ & $\begin{array}{c}\text { Foreign trade } \\
\text { share }\end{array}$ & Growth $^{\mathrm{c}}$ \\
\hline $\mathrm{TO}_{1975}$ & 1.00 & 0.35 & 0.33 & 0.73 \\
$\mathrm{I} / \mathrm{Y}_{70-80} \mathrm{~d}$ & & 1.00 & 0.30 & 0.54 \\
Foreign trade share & & & 1.00 & 0.39 \\
Growth & & & & 1.00 \\
\hline
\end{tabular}

${ }^{\text {a }} \mathrm{TO}_{1975}$ : Trade orientation 1975 (Chenery and Syrquin, 1986).

b (Exports + Imports) / nominal GDP. Average for 1970-1980 period (Penn World Tables, Mark 5.6).

c Growth : growth rate of real GDP per worker 1960-1990 (Penn World Tables, Mark 5.6).

Intra-industry trade: index of intra-industry trade 1982 (Leamer, 1988).

Trade intensity: adjusted index of trade intensity 1982, Leamer 1 (Leamer, 1988).

${ }^{\mathrm{d}} \mathrm{I} / \mathrm{Y}_{70-80}$ : Share of investment in GDP. Average for 1970-1980 period ((Penn World Tables, Mark 5.6).

commodity exports. In reality, they were converging towards a higher equilibrium level of income, as the analysis made in section II suggests.

It may be noted that the results presented here tend to confirm the findings of recent studies (Sachs and Warner, 1997; Sala-i-Martin, 1997), which show that, after controlling for other variables, economies specializing in the production and export of goods making intensive use of natural resources tend to grow more slowly than those specializing in the export of manufactures. According to Sachs and Warner, abundance of natural resources, as measured by the percentage of GDP accounted for by exports making intensive use of natural resources, has a negative effect 
on growth: an influence that the authors attribute to "Dutch Disease"-type effects. These authors experiment with other measures of abundance of natural resources (such as the share of commodity exports in total exports, or the amount of land per capita), with results that confirm this negative relation. According to Sala-iMartin, exports of primary commodities as a proportion of total exports is one of the few economic variables which is systematically (negatively) correlated with growth.

\section{Trade openness, investment and growth}

In their "sensitivity analysis" of cross-country growth regressions, Levine and Renelt (1992) examined the robustness of the empirical relations between long-term growth and a variety of economic, political and institutional indicators. Their findings were pessimistic. Although there are many econometric specifications in which various indicators are significantly correlated with per capita growth rates, almost all these specifications are fragile in the sense that small alterations in the "other" explanatory variables change the results previously obtained. Only two relations pass this test. One is the positive correlation between growth and the investment rate (investment as a percentage of GDP). The other is the positive correlation between the share of foreign trade in GDP and the investment rate. Table 3 presents results that support these conclusions for the large sample of 34 countries: the positive correlation between growth and the investment rate $(0.54)$ and that between the share of foreign trade and the investment rate $(0.30)$.

The first result is reassuring because it coincides with economic theory. The second is a puzzle, however. Firstly, it is important to note that the robust relation found by Levine and Renelt is not between the investment rate and trade barriers, but between the investment rate and the share of foreign trade. The relations between the investment rate (or the growth rate) and various indicators of trade barriers or distortions in foreign trade policy are not robust ${ }^{8}$, so the robust relation does not seem to reflect the effects

\footnotetext{
${ }^{8}$ These indicators include "real exchange rate distortion" (Dollar, 1992), the average premium on the currency black market, and Chenery and Syrquin's trade openness index. In a more recent review of the literature on trade policy and growth (after the publication of Levine and Renelt's article), Rodríguez and Rodrik (1999) conclude that trade policy indicators lack statistical significance in well-specified cross-country growth regressions.
}

of trade policy. Secondly, when controlled for the investment rate, there is no robust relation between the share of foreign trade and growth (provided of course that the indicator used is the share of exports and/or imports). The fact that the robust relation is between trade and the investment rate suggests that if trade affects growth it does not do so through the conventional channels involving resource allocation but through less conventional channels involving positive effects on the investment rate.

What these channels can be is not clear from the existing literature. Romer (1990 a and b) suggests that trade openness has a positive effect on research and development expenditure and, by thus increasing the rate of technological change, influences the investment and growth rates. Other points of view stress the positive effects of trade openness on technology transfer. ${ }^{9}$ Whatever the merits of these views, they hardly represent a convincing explanation of Levine and Renelt's findings. One reason is that the trade openness considered in these models does not refer to the share of trade in GDP and therefore any attempt to provide an explanation of the statistical relation between the share of trade and the investment rate runs up against an old objection recently restated by De Long and Summers (1991). The share of trade is influenced by the size of a country and its proximity to its trading partners. If Belgium and the Netherlands were to merge, it would be difficult to imagine how much the combined rate of technical progress should go down (or increase) because this new entity would be less "open" than each of the two countries separately. ${ }^{10}$

Even if the objection against measuring trade openness by the share of foreign trade were not decisive, however, the following question remains: Why is the robust correlation only between investment and trade

\footnotetext{
${ }^{9}$ At the same time, it can be argued that the effects of trade openness depend on the specialization pattern induced by the greater openness (as in the model in section II). In some North-South models, such as that of Young (1991), trade openness can even result in a slower rate of technological change in the South. Moreover, foreign direct investment is a major vehicle for technology transfer but there is no clear relation between trade openness and openness to foreign direct investment.

${ }^{10}$ It should be noted that De Long and Summers' observation is not an objection against models in which trade openness -in the sense of the absence of trade barriers- has a positive effect on investment. It is rather an objection against the use of the share of foreign trade in GDP as a measure of trade openness. The implication, however, is that we must not interpret the correlation between investment and the share of foreign trade as evidence in support of models in which openness stimulates investment.
} 
share and not between investment and other (more appropriate) measures of trade openness? The analysis made in this and earlier sections suggests various hypotheses which can provide a convincing explanation of the positive relation between trade share and the investment rate. ${ }^{11}$ Our line of argument will be that the link between trade and investment involves the specialization pattern as determined by policies and factor endowment, including natural resources. The studies on differences in growth rates between countries have ignored these links because, with a few recent exceptions, they have ignored the influence these two factors (industrial policy and resource endowment) exert through their effects on trade orientation. ${ }^{12}$

The nub of the argument is that the positive correlation between trade share and the investment rate is measured by the trade orientation; in other words, the explanation of the positive relation is that the trade share and investment rate are both positively affected by a bias towards manufactures in trade orientation. We have already analysed and illustrated the effects of trade orientation on the investment rate. We will now look at the effects of trade orientation on trade share. Table 1 shows a positive relation between these two variables, while tables 2 and 3 show positive coefficients of correlation of 0.35 and 0.33 .

Why should a specialization pattern based on the export of manufactures have a positive effect on trade share? One reason is the positive effect that

\section{VI}

\section{Conclusions}

This study offers an analytical framework for analysing the relations between the specialization pattern and growth, together with empirical evidence which does indeed suggest that the specialization pattern is an im-

\footnotetext{
${ }^{11}$ We have already mentioned the argument put forward by Rodrik (1995) whereby a higher investment rate can lead to a higher trade share as a result of an increase in imports of capital goods in economies which are in the process of industrialization. In this argument, the causality is from investment to trade and not in the opposite direction. In the following paragraphs of this article our ideas will follow a different direction which is complementary to the foregoing.

${ }^{12}$ As already mentioned, the exceptions include Sachs and Warner (1997) and Sala-i-Martin (1997).
}

specialization in activities with increasing returns can have on trade creation. The increasing returns favour the expansion of intra-industry trade -two-way trade flows of similar products with economies of specialization. Countries with a bigger bias towards manufactures in their exports usually have higher indexes of intra-industry trade. The correlation coefficient between the two indexes, as shown in table 2, is 0.69 .

A second reason may be the presence of "Dutch Disease"-type effects of exports of primary commodities. What the "Dutch Disease" models imply is that commodity-exporting countries tend to be less open (other things being equal), because in the long-term equilibrium they have bigger non-tradeable goods sectors (see Ros, 2000, chapter 8). It may be noted in this respect that trade orientation towards manufactures has a positive relation with Leamer's trade openness index. This is an adjusted trade intensity index which represents the difference between the observed level of trade (not the trade pattern) and the level predicted by a Heckscher-Ohlin model, which includes factor endowment and distance to markets. The positive relation with trade orientation indicates that the more biased the trade orientation is towards commodity exports, the lower the index of trade intensity tends to be, probably because of the existence of larger non-tradeable goods sectors and lower levels of intra-industry trade. portant determinant in the growth process. The analysis showed the scope and limitations of industrial policy. On the one hand, it showed how an industrial policy which reallocates resources towards sectors with potential to exploit economies of scale and specialization can raise the growth rate of an economy by increasing the capital yield and capital accumulation rate. On the other hand, it clearly revealed that the efficacy of industrial policy depends on the presence of certain conditions -especially physical and human capital endowment and a sufficiently broad market for sectors with economies of scale and specialization- which do indeed allow the reallocation of resources to raise the profit rate in the new spearhead sectors. 
The empirical analysis tended to confirm that economies oriented towards the export of manufactures tend to grow faster than those oriented towards commodity exports. Among the semi-industrialized countries, there are no examples of super-growth based on the export of goods making intensive use of natural resources. ${ }^{13}$ This does not mean that countries with an abundance of such resources must change their specialization pattern in order to grow faster. Efforts in this direction would probably be a failure in many of them, precisely because the efficacy of industrial policy is conditioned by factor endowment. Nor does it mean that these countries with an abundance of natural resources are doomed to grow more slowly than countries with a bias towards exports of manufactures, since they can speed up their growth process by trying to influence other determinants of that process.

Finally, it should be noted that in this article the economic policy implications are limited by the type of externalities considered. The external effects of a pecuniary and dynamic nature which take place between producers of capital-intensive goods and producers of intermediate goods operating in conditions of increasing returns give rise to flaws in coordination whose solution calls for public intervention. However, the study did not deal with other types of externalities and market flaws (especially in factor markets) which justify interventions generally included under the heading of industrial policy.

(Original: Spanish)

\section{Appendix: The formal model ${ }^{14}$}

There are two sectors producing tradeable goods in the economy (denoted by 1 and 2). The technology used in both sectors is of the Cobb-Douglas type:

$$
Q_{1}=K_{1}^{b} L_{1}{ }^{1-b} \quad Q_{2}=K_{2}^{a} I^{1-a}
$$

where $K$ is the capital input and $L$ is the labour input. Let us assume that $a>b$, that is to say, sector 2 is more capitalintensive than sector 1 . I represents the input consisting of a set of intermediate goods:

$$
I=\left(\Sigma(1 / n) I i^{\sigma}\right)^{1 / s} \quad 0<\sigma<1,
$$

where $n$ is the number of intermediate goods, assumed to be given. The sector producing these intermediate goods (sector 3 ) does so using labour in conditions of increasing returns to scale:

$$
I_{i}=L_{i}^{1+\mu} \quad \mu>0
$$

where $L_{i}$ is the labour input.

The enterprises in the three sectors maximize their benefits, taking the prices of the inputs as given. The enterprises in sectors 1 and 2 also take the prices of the goods produced as given. In both sectors the capital stock is predetermined. The levels of use of the factors variable in the short term are derived from the first-order conditions for the maximization of benefits:

$$
L_{1}=\left[(1-b) p_{1} / w\right]^{1 / b} K_{1}
$$

\footnotetext{
${ }^{13}$ Although Botswana can hardly be described as a semiindustrialized economy, it comes closest to being an exception to this. The sustained progress of this economy seems to have been the result of a series of mining booms (diamond mining) within the context of a stable macroeconomic policy.

${ }^{14}$ This appendix is based on Ros (2000), chapters 5 (sections 2 and 3), 8 (section 3) and 9 (section 1).
}

$$
I=(1-a)^{1 / a}\left(p_{3}, p_{2}\right)^{-1 / a} K
$$

where $w$ is wages, $p_{1}$ and $p_{2}$ are the prices of goods 1 and 2, and $p_{3}$ is the (minimum) cost of a basket of intermediate goods such that $\mathrm{I}=1$.

In sector 3, the producers operate in conditions of monopolistic competition and face downward-sloping demand curves:

$$
I_{i}^{d}=D p_{i}^{-\eta} \quad \eta>1
$$

where $D$ reflects the position on the demand curve and $\eta$ is the price elasticity of demand faced by individual producers. This elasticity is a function of $\sigma, a$ and $n$, and for large values of $n$ is given approximately by $1 /(1-\sigma)$. The inequality in [4] is due to the parametric restrictions $0<a<1$ and $0<\sigma<1$.

Based on the demand function in [4] and production function [1], the optimal price decision of an individual producer of intermediate goods is a profit margin $(\pi)$ over the marginal cost $(\omega)$ :

$$
p_{i}=(1+\pi) \omega
$$

where:

$$
1+\pi=[\eta /(\eta-1)] \quad \omega=w /(1+\mu) I i^{\mu /(1+\mu)}
$$

Equations [4] and [5] are combined with the input demand of sector 2 (equation [3]) to find a solution for $I, p_{3}$ and $D$. Using [1] and the solution for $I$, we obtain the level of employment in sector 3:

$$
\begin{gathered}
L_{3}=\left[(1 / n)^{1-f} G K_{2}^{a} p_{2} / w\right]^{1 / f} \\
G=(1-a)(1+\mu)(\eta-1) / \eta \\
f=\mathrm{a}-\mu(1-\mathrm{a})
\end{gathered}
$$




\section{Equilibrium in the labour market}

Equilibrium in the labour market means a uniform rate of wages in sectors 1 and 3, with full employment of the labour force (L): $\mathrm{L}=\mathrm{L}_{1}+\mathrm{L}_{3}$. Let us consider what happens with the equilibrium wage when capital is reallocated from sector 1 to sector 2. At the initial level of wages, the reduction in the stock of capital in sector 1 causes a decline in the demand for labour in that sector. Using the labour demand equation for $\mathrm{L}_{1}$ and keeping wages constant, the reduction in employment in sector 1 is given by:

$$
-\mathrm{dL}_{3}=\left[(1-\mathrm{b}) \mathrm{p}_{1} / \mathrm{w}\right]^{1 / \mathrm{b}}\left(-\mathrm{dK}_{1}\right)
$$

The greater stock of capital in sector 2 causes an increase in the demand for labour in sector 3. Using the demand function for $\mathrm{L}_{3}$, the increase in employment in sector 3 at the initial wage level is:

$$
\mathrm{dL}_{3}=\left[(1 / \mathrm{n})^{1-\mathrm{f}} \mathrm{G} \mathrm{p}_{2} / \mathrm{w}\right]^{1 / \mathrm{f}}(\mathrm{a} / \mathrm{f}) \mathrm{K}_{2}{ }^{(\mathrm{a} / \mathrm{f})-1} \mathrm{dK}_{2}
$$

with $-d K_{1}=d K_{2}$, on the assumption that the reallocation does not affect the total stock of capital. Whether the change gives rise to an excess supply or demand for labour depends on the size of $\left(-d L_{1}\right)$ compared with $\left(d L_{3}\right)$. Obviously, the answer depends on the level of $K_{2}$. When $K_{2}$ is small, sector 3 is also small and produces at very high costs, in view of the existence of economies of scale in this sector. As the relative price of intermediate inputs $\left(p_{3} / p_{2}\right)$ is very high, the capital intensity $(K / I)$ in sector 2 is also very high, even though the absolute value of $K_{2}$ is small. With a high value of the ratio $(K / I)$, the increase in the stock of capital in sector 2 has only small indirect effects on employment in sector 3 . The reduction in the demand for labour in sector 1 is then greater than the increase in the demand for labour in sector 3. A reallocation of capital from sector 1 to sector 2 thus tends to create an excess supply of labour, and this requires a reduction in wages in order to clear the labour market.

In contrast, when the level of $K_{2}$ is high, the indirect effects of the expansion of sector 2 on employment may outweigh the reduction in the demand for labour in sector 1 . The greater scale of sector 3 has made it more productive and reduced the relative price of intermediate goods. With a lower level of capital intensity $(K / I)$, the expansion of sector 2 at the expense of sector 1 may then have the effect of giving rise to excess demand for labour and increasing the equilibrium wage.

We can formally verify that a reallocation of capital to sector 2 should first of all have the effect of lowering the equilibrium wage but later on have the effect of raising it. Substituting the labour demand functions in the full employment condition, we can derive an equilibrium locus for the labour market which shows the equilibrium wage for different compositions of the capital stock. Keeping $K$ constant, the slope of this locus in the space $\left(\log w, \log K_{2}\right)$ is:

$d \log w / d \log K_{2}=\left[a / f-\left(K_{2} / K_{1}\right)\left(L_{1} / L_{3}\right)\right] /\left[1 / f+(1 / b)\left(L_{1} / L_{3}\right)\right]$

where $L_{1} / L_{3}$, using the labour demand functions, is given by:

$$
\begin{gathered}
\mathrm{L}_{1} / \mathrm{L}_{3}=\left(\mathrm{B} \mathrm{K}_{1} / \mathrm{A} \mathrm{K}_{2}^{\mathrm{a} / \mathrm{f}}\right) \mathrm{w}^{1 / \mathrm{f}-1 / \mathrm{b}} \\
B=\left[(1-b) p_{1}\right]^{1 / b} \quad A=\left[(1 / n)^{1-f} G p_{2}\right]^{1 / f}
\end{gathered}
$$

As we can see, the slope of this locus is negative, tending towards zero at low levels of $K_{2}$ but becoming positive and tending towards " $a$ " at high levels of $K_{2}$ (on condition that such high values exist because of the size of the total capital stock). Consequently, the equilibrium value of wages first goes down as $K_{2}$ increases and subsequently rises, becoming a growing function of $K_{2}$ (see figure 1).

\section{Equilibrium in the capital market}

Using the definition of the profit rate and the first-order conditions for maximizing benefits in sectors 1 and 2, the rates of profitability in these sectors may be expressed as inverse functions of the wage rate:

$$
\begin{gathered}
r_{1}=b\left(p_{1} / p_{2}\right)\left[(1-b) p_{1} / w\right]^{(1-b) / b} \\
r_{2}=a K_{2}^{\mu(1 / a) / f}\left[(1 / n) G /\left(w / p_{2}\right)\right]^{(1-f) / f}
\end{gathered}
$$

Capital is assumed to be mobile between sectors 1 and 2. Equilibrium in the capital market requires full use of the total stock of capital $(K)$ and equal rates of profitability in the two sectors using capital (insofar as these two sectors exist side by side):

$$
K=K_{1}+K_{2} \quad r_{1}=r_{2}
$$

By replacing the expressions for the profit rate in the condition of equality between the two rates, we can derive the equation for an equilibrium locus in the capital market. In the space $\left(w, K_{2}\right)$, this locus shows the value of $K_{2}$ for each given value of wages and the corresponding composition of the capital stock which gives the same rate of profitability in sectors 1 and 2. So, if there is an increase in wages, how must the composition of the capital stock change in order to maintain equilibrium in the capital market? Intuitively, the answer to this question depends on which of the two sectors makes the most intensive use of labour. Higher wages will naturally tend to cause a bigger reduction in the profitability of the sector which makes the most intensive use of labour. The reallocation required would therefore depend on the 
FIGURE 1 Specialization pattern for increasing returns to scale

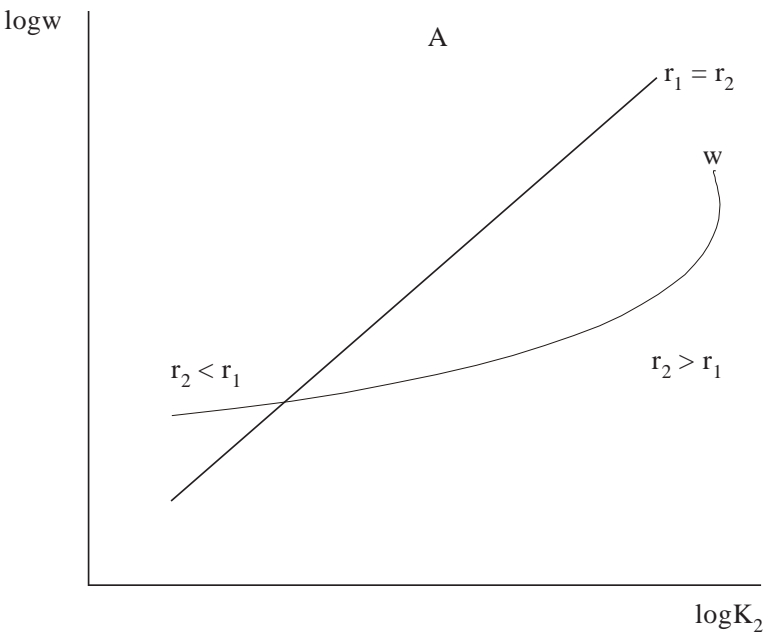

effects of $K_{2}$ on the relative rates of profitability. ${ }^{15}$ The problem is that in this model it is not clear which of the two sectors makes the most intensive direct and indirect use of labour. Although the use of capital in sector 2 is more intensive than in sector 1 (in the sense that $a>b$ ), the parameter of increasing returns $(\mu)$ may be sufficiently great to cause the "indirect" share of labour in sector 2 to be greater than the share in sector 1 . This is because of the presence of returns to scale in sector 3, which causes the sum of the shares of capital and labour in the "integrated" sectors 2 and 3 to be greater than unity.

Formally, the slope of the locus for capital market equilibrium in the space $\left(\log w, \log K_{2}\right)$ is given by:

$$
d \log w / d \log K_{2}=[\mu(1-a) / f] /[(1-a)(1+\mu) / f-(1-b) / b]
$$

We have, in fact, two different cases, depending on the technology parameters for the three sectors. Section A of figure 1 shows the case where $b>f$. This means that $(1-a)(1+\mu)>$ $(1-b)$, that is to say, that the "indirect" share of labour in sector 2 is greater than the share of labour in sector 1 . In this case, an

${ }^{15}$ If there is no effect -that is to say, if $K_{2}$ does not appear in the equation for the rate of profitability of sector $2-$ there will be no reallocation capable of restoring the equality of the rates of profitability. In this case, the locus would be a horizontal straight line corresponding to the single value of wages consistent with equality of the rates of profitability. As may be seen, this is the case if $\mu=0$ : that is to say, if the technology of the integrated sector $2 / 3$ has constant returns to scale.

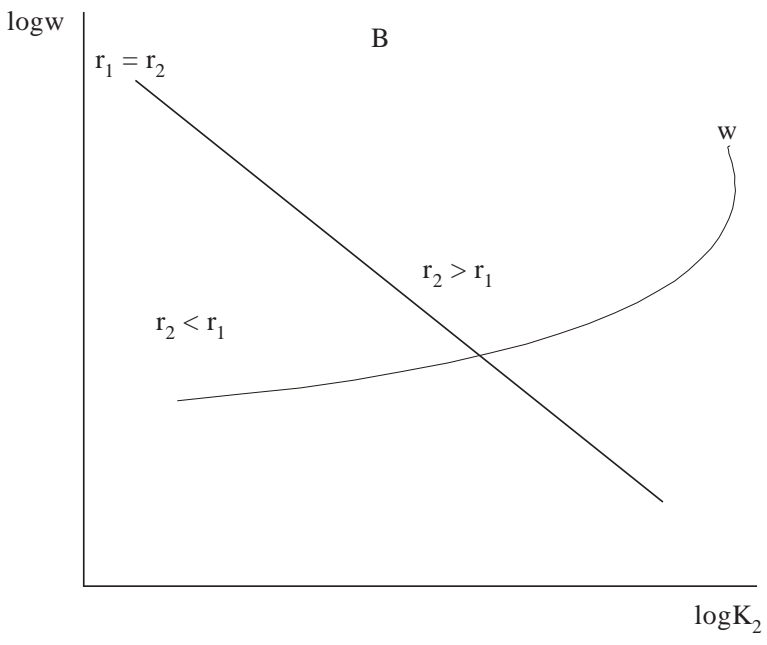

increase in wages ( $K_{2}$ being given) reduces the rate of profitability in sector 2 more than in sector 1 . An increase in $K_{2}$ (which has a positive effect on $r_{2}$ ) is therefore required in order to restore equality of profit rates. This means that the slope of the locus is positive.

In the second case (section B of figure 1), we have $b<f$. This means that $(1-a)(1+\mu)<(1-b)$ : in other words, the "indirect" share of labour in sector 2 is less than in sector 1 . In this case, an increase in wages ( $K_{2}$ being given) will reduce the profitability of sector 1 more than that of sector 2 . This requires a reduction in $K_{2}$ (which reduces $r_{2}$ ) in order to restore equality of rates of profitability. The slope of the locus is then negative.

In the two configurations shown in figure 1, the area to the right of the locus $r_{1}=r_{2}$ is such that sector 2 is more profitable than sector 1 . This is because it is an area in which $K_{2}$ is relatively large for each given level of wages, and $K_{2}$ has a positive effect on the relative profitability of sector 2 . Thus, on the right of the locus capital will flow to sector 2 and the ratio $K_{2} / K_{1}$ will tend to increase. To the left of the locus $r_{1}=r_{2}$, in contrast, the profitability of sector 2 is less than that of sector 1 and capital will flow to sector 1 . It follows from this that in both cases the composition of the capital stock corresponding to the intersection of the two loci is an unstable equilibrium. As the figure shows, allocation of the capital stock with a level of $K_{2}$ which is higher than at the intersection generates a profit rate in sector 2 which is higher than that of sector 1. Capital thus moves to sector 2 and further depresses the relative profitability of sector 1. Similar mechanisms, in the opposite direction, operate 
for capital allocations in which $K_{2}$ is lower than at the intersection. ${ }^{16}$

\section{Multiple equilibria}

We can also verify that when the two curves intersect, this intersection is unique. ${ }^{17}$ Consequently, if an intersection exists there will be two stable equilibria in which the whole of the capital stock is invested in one of the two sectors. In one equilibrium, the economy is completely specialized in sector 1 . As in this case there is no sector 3, not only the whole of the capital stock but also the whole of the labour force is employed in sector 1 . In the other equilibrium, the economy is specialized in the production and export of the goods produced in sector 2, and as there is no sector 1 the whole of the labour force is employed in sector 3 .

In our economy, there is always an equilibrium with specialization in sector 1 , regardless of whether or not there are multiple equilibria. As already noted in the article, this is because of the assumption that sector 1 does not use intermediate inputs produced under conditions of increasing returns. At low levels of $K_{2}$, the profitability rate of sector 2 will tend towards zero, while it will remain positive in sector 1 however large the capital stock is. There are therefore capital allocations at sufficiently low levels of $K_{2}$ for which sector 1 is more profitable than sector 2 .

As there is always an equilibrium with specialization in sector 1 , it follows that the existence of an equilibrium with specialization in sector 2 ensures the existence of an intersection and hence also ensures the existence of multiple equilibria. Likewise, an equilibrium with specialization in sector 2 exists if the profitability of sector 2 , when the whole of the capital stock is invested in that sector, is greater than that of sector 1 (valued at the market equilibrium wage corresponding to $L=L_{3}$ ). Let us first of all consider the wage with specialization in sector $2\left(w_{2}^{*}\right)$. Using [6] and the conditions $L_{3}=L$ and $K_{2}=K$, and solving the equation for the wage, we have:

\footnotetext{
16 The instability of the capital allocation corresponding to the intersection is due to the existence of increasing returns to scale in the integrated sector $2 / 3$. At constant returns to scale, the labour market equilibrium locus has a negative slope (if the integrated sector $2 / 3$ is the capital-intensive sector), while the capital market equilibrium locus is a horizontal straight line (see footnote 15). As the reader can see, in this case the equilibrium corresponding to the intersection is stable.

${ }^{17}$ In case $\mathrm{A}$, this is because the capital market equilibrium locus has a more pronounced slope than the labour market equilibrium locus at high levels of $K_{2}$. The necessary and sufficient conditions for this are that $a>b$ and $f>0$. In case $\mathrm{B}$, the intersection is unique because the capital market locus has a steeper slope, at low levels of $K_{2}$, than the labour market locus.
}

$$
w_{2}{ }^{*}=G(1 / n)^{1-f} p_{2} K^{a} / L^{f}
$$

Substituting [9] in [8], and making $w_{2} *$ equal to $w_{2}$ and $K_{2}$ equal to $K$, we obtain the profitability rate for the equilibrium with specialization in sector $2\left(r_{2} *\right)$ :

$$
r_{2}^{*}=a(L / n)^{1-f} / K^{1-a}
$$

The profitability rate in sector 1 , valued at wage $w_{2}{ }^{*}$, is obtained by substituting [9] in [7]:

$$
r_{2}{ }^{l}=b\left(p_{1} / p_{2}\right)^{1 / b}\left[(1-b) n^{1-f} L^{f} / G K^{a}\right]^{(1-b) / b}
$$

It should be noted that the profitability rate of sector 1 , $r_{2}{ }^{l}$, valued at wage $w_{2}{ }^{*}$, is an increasing function of the number of producers of intermediate goods $(n)$. A larger number of producers increases the unit cost of each of the intermediate goods and reduces the demand for labour in sector 3 . This has a negative effect on $w_{2} *$ and thereby tends to increase the rate of profitability in sector 1 , which does not use intermediate goods. This negative effect on wages is offset in the case of the profitability rate of sector 2 , since a larger number of producers implies higher costs in sector 2 : $r_{2} *$ is a decreasing function of the number of producers $(n)$.

Using [10] and [11], the condition for $r^{*}>r_{2}{ }^{l}$ and, hence, for the existence of multiple equilibria, is:

$$
K^{a-b}>K^{* a-b}=(b / a)^{b}\left(p_{1} / p_{2}\right)[(1-b) / G]^{I-b} n^{I-f} L^{f-b}
$$

The existence of multiple equilibria depends on the endowment of capital and labour and the relative prices. In particular, the total stock of capital must be sufficiently large to ensure that, when the whole of that stock is invested in sector 2, the price of intermediate goods is sufficiently low to make that sector viable. The critical value $\left(K^{*}\right)$ of the total stock of capital increases with the relative price $\left(p_{1} / p_{2}\right)$, which increases the profitability of sector 1 . That profitability also increases with the number of enterprises $(n)$ in sector 3 , which adversely affects the profitability of sector 2 . The effect of the size of the labour force on the critical value of the capital stock depends on the sign of $(f-b)$, that is to say, on the "indirect" share of labour in sector 2 compared with sector 1 .

Let us assume that the conditions for the existence of multiple equilibria are fulfilled, and let us then compare the wages and profitability rates in the two equilibria. In the equilibrium with specialization in sector 2 , the rates of wages and profitability are given by equations [9] and [10]. In the equilibrium with specialization in sector 1 , we have $K_{l}=K$ and $L_{1}=L$. Using equations [2] and [7], the wages and rates of profitability in the equilibrium with specialization in sector 1 are: 


$$
\begin{gathered}
w_{1}^{*}=(1-b) p_{1}(K / L)^{b} \\
r_{1}^{*}=b\left(p_{1} / p_{2}\right)(L / K)^{1-b}
\end{gathered}
$$

Comparison of [10] and [14] shows that $r_{2} *$ is greater than $r_{1} *$ if:

$$
K^{a-b}>K^{* * a-b}=(b / a)\left(p_{1} / p_{2}\right) n^{1-f} L^{f-b}
$$

Comparing [12] and [15] we can establish that $K^{*}>$ $K^{* *}$. The assumption that $a>b$ and the second-order condition for a maximum of producers of intermediate goods guarantee this inequality. ${ }^{18}$ Consequently, when an equilibrium with specialization in sector 2 exists $\left(K>K^{*}\right)$, the rate of profitability in this equilibrium is greater than in the equilibrium with specialization in sector 1 (since $K$ is then greater than $K^{* *}$ ).

Examination of [9] and [13] shows that for $w_{2} *$ to be greater than $w_{1}^{*}$ the total stock of capital must be such that:

$$
K^{a-b}>K^{* * * a-b}=(1-b)\left(p_{1} / p_{2}\right) n^{1-f} L^{f-b} / G \quad \text { [16] }
$$

From [12] and [16] we can establish that $K^{* * *}>K^{*} .19$ The existence of an equilibrium with specialization in sector 2 does not ensure that the wages in that equilibrium are higher than in the equilibrium with specialization in sector 1 . For this to take place, the capital stock must be greater than $K^{* * *}$. In that case, with $K>K^{* * *}$ and hence with $K$ greater than $K^{*}$ and $K^{* *}$, there is an equilibrium with specialization in sector 2 which has both profitability rates and wages higher than in the equilibrium with specialization in sector 1 .
${ }^{18} K^{*}>K^{* *}$ if the following condition is fulfilled:

$$
(1-b) / b>[(1-a) / a](1+\mu)(1-1 / \eta)
$$

$a>b$ means that $(1-b) / b>(1-a) / a$. In order for the second-order condition for the maximization of benefits among producers of intermediate goods to be fulfilled, it is necessary that $(1+\mu)(1-1 / \eta)$ $<1$. Together, these inequalities ensure the fulfillment of the above condition.
${ }^{19}$ This requires, as in the previous case:

$$
(1-b) / b>[(1-a) / a](1+\mu)(1-1 / \eta)
$$

This inequality is guaranteed by the conditions mentioned earlier ( $a>b$ and the second-order condition for the maximization of benefits among the producers of intermediate goods). 


\section{Bibliography}

Amsden, A. (1989): Asia's Next Giant. South Korea and Late Industrialization, New York, Oxford University Press.

Chenery, H.B. and M. Syrquin (1975): Patterns of Development, 1950-1970, London, Oxford University Press.

(1986): The semi-industrial countries, in H.B. Chenery, S. Robinson and M. Syrquin, Industrialization and Growth. A Comparative Study, Washington, D.C., World Bank.

Ciccone, A. and K. Matsuyama (1996): Start-up costs and pecuniary externalities as barriers to economic development, Journal of Development Economics, vol. 49, No. 1, Amsterdam, The Netherlands, Elsevier Science Publishers, B.V.

Corden, W. M. (1984): Booming sector and Dutch disease economics: Survey and consolidation, Oxford Economic Papers, vol. 36, No. 3, London, Oxford University Press.

De Long, J.B. and L. Summers (1991): Equipment investment and economic growth, Quarterly Journal of Economics, vol. 106, No. 2, Cambridge, Massachusetts, The MIT Press.

Dollar, D. (1992): Outward-oriented developing economies really do grow more rapidly: Evidence from $95 \mathrm{LDCs}$ 1976-1985, Economic Development and Cultural Change, vol. 40, No. 3, Chicago, Illinois, The University of Chicago.

Ethier, W. J. (1982): National and international returns to scale in the modern theory of international trade, American Economic Review, vol. 72, No. 3, Nashville, Tennessee, American Economic Association.

Hong, W. (1993): Trade and development: The experience of Korea and Taiwan, in G. Hasson (ed.), International Trade and Development, London, Routledge.

Kaldor, N. (1967): Strategic Factors in Economic Development, The Frank W. Pierce Memorial Lectures at Cornell University, October 1966, Ithaca, New York, Cornell University.

Krugman, P. (1987): The narrow moving band, the Dutch disease, and the competitive consequences of Mrs. Thatcher: Notes on trade in the presence of dynamic scale economies, Journal of Development Economics, vol. 27, Nos. 1-2, Amsterdam, The Netherlands, Elsevier Science Publishers, B.V.

Leamer, E. (1988): Measures of openness, in R. Baldwin (ed.), Trade Policy Issues and Empirical Analysis, NBER Conference Report Series, Chicago, Illinois, University of Chicago Press.
Levine R. and D. Renelt (1992): A sensitivity analysis of cross-country growth regressions, American Economic Review, vol. 82, No. 4, Washington, D.C., American Economic Association.

Lin, C. (1973): Industrialization in Taiwan, 1946-72: Trade and Import Substitution Policies in Developing Countries, New York, Praeger.

Matsuyama, K. (1992): Agricultural productivity, comparative advantage and economic growth, Journal of Economic Theory, No. 58, New York, Academic Press.

Rodríguez-Clare, A. (1996): The division of labor and economic development, Journal of Development Economics, vol. 49, No. 1, Amsterdam, The Netherlands, Elsevier Science Publishers, B.V.

Rodríguez, F. and D. Rodrik (1999): Trade Policy and Economic Growth: A Skeptic's Guide to the CrossNational Evidence, NBER working paper, No. 7081, Cambridge, Massachusetts, National Bureau of Economic Research (NBER)

Rodrik, D. (1995): Getting interventions right: How South Korea and Taiwan grew rich, Economic Policy, No. 20, London, Centre for Economic Research, April.

Romer, P. (1990a): Capital, Labor and Productivity, Brookings Papers on Economic Activity, special issue, Washington D.C, The Brookings Institution.

(1990b): Endogenous technical change, Journal of Political Economy, vol. 98, No. 5, Chicago, Illinois, The University of Chicago Press.

Ros, J. (2000): Development Theory and the Economics of Growth, Michigan, University of Michigan Press.

Sachs, J.D. and A.M. Warner (1997): Natural Resource Abundance and Economic Growth, Cambridge, Massachusetts, Harvard Institute for International Development

Sala-i-Martin, X. (1997): I just ran two million regressions, American Economic Review, vol. 87, No. 1, Washington, D.C., American Economic Association, May.

Skott, P. and J. Ros (1997): The 'big push' in an open economy with non-tradable inputs, Journal of Post Keynesian Economics, vol. 20, Armonk, New York, M.E. Sharpe Inc., Fall (p. 5).

Young, A. (1991): Learning by doing and the dynamic effects of international trade, Quarterly Journal of Economics, vol. 106, No. 2, Cambridge, Massachusetts, MIT Press.

Wade, R. (1990): Governing the Market: Economic Theory and the Role of Government in East Asian Industrialization, Princeton, New Jersey, Princeton University Press. 